\title{
Retrofitting strategies for improving the energy and environmental efficiency in industrial furnaces: A case study in the aluminium sector
}

\author{
Patricia Royo, Víctor José Ferreira, Ana M. López-Sabirón, Tatiana García-Armingol, \\ Germán Ferreira \\ Research Centre for Energy Resources and Consumption (CIRCE), CIRCE Building - Campus Río Ebro, Mariano Esquillor Gómez, 15, 50018 Zaragoza, Spain
}

\section{A R T I C L E I N F O}

\section{Keywords:}

Life cycle assessment

Environmental impact assessment

Monetarization

Life cycle costs

Direct current

Retrofitting furnaces

\begin{abstract}
A B S T R A C T
This study aims to analyse some of the most relevant issues that the energy intensive industry needs to face in order to improve its energy and environmental performance based on innovative retrofitting strategies. To this end, a case study based on the aluminium industry, as one of the most relevant within the European energy intensive industry has been thoroughly discussed. In particular, great efforts must be addressed to reduce its environmental impact; specifically focusing on the main stages concerning the manufacturing of an aluminium billet, namely alloy production, heating, extrusion and finishing. Hence, an innovative DC (direct current) induction technology with an expected 50\% energy efficiency increase is used for retrofitting conventional techniques traditionally based on natural gas and AC (alternating current) induction. A life cycle assessment was applied to analyse three different scenarios within four representative European electricity mixes. The results reported reductions up to $8 \%$ of Green House Gases emissions in every country. France presented the best-case scenario applying only DC induction; unlike Greece, which showed around $150 \%$ increment. However, the suitability of the new DC induction technology depends on the electricity mix, the technological scenario and the environmental impact indicators. Finally, environmental external costs were assessed with comparison purposes to evaluate the increase of energy and environmental efficiency in existing preheating and melting industrial furnaces currently fed with natural gas.
\end{abstract}

\section{Introduction}

Energy intensive industries, including sectors such as che7micals, steel, aluminium, cement, ceramics and paper, are responsible for great environmental, economic and social impacts. About $3 \%$ of world's total energy is used in industrial sectors and the world power demand represented around 60 billion MW in 2015 [1]. Unfortunately, there is usually strong overlap of interest for energy-intensive industries and climate change goals [2]. Many efforts are focused on decarbonising the manufacturing industry by means of key actions such as fuel switching to less carbon intensive fuels, carbon capture and storage and alteration of the product design taking into account the lifecycle of the product [3]. So they are continuously facing new challenges in order to increase the efficiency, reliability and flexibility of their processes. However these changes disrupt the production or require sometimes high investment or an in-depth renovation process [4]; thus retrofitting strategies arise as promising and more cost-efficient actions in industrial plants. Most notably, industrial furnaces have been the focus of multiple researches as one of the most energy intensive processes [5], representing more than $40 \%$ of the energy consumption in European industry sector [6].

The main goals of retrofitting strategies are focused on addressing radical improvements in the competitiveness and energy, environmental and cost performance, which can be implemented at component, process, system, and organizational level [7]. To that end, the development of improved designs based on new materials and/or technologies, alternative feedstocks, equipment and the integration of permanent monitoring and control systems into new and existing furnaces seem to be essential instrument to meet the demands. A retrofitting action should be carefully weighed against the benefits and costs of new

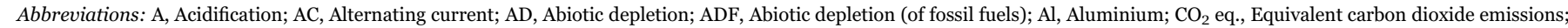

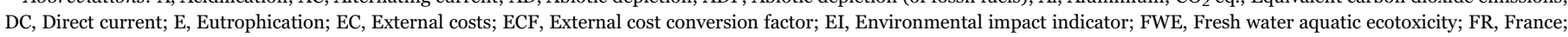

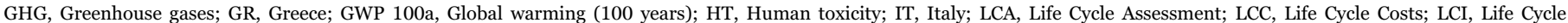
Inventory; MAE, Marine aquatic ecotoxicity; NG, Natural Gas; ODP, Ozone layer depletion; PO, Photochemical oxidation; S, Scenario; SP, Spain; TE, Terrestrial ecotoxicity

* Corresponding author.

E-mail addresses: proyo@fcirce.es (P. Royo), vferreira@fcirce.es (V.J. Ferreira), amlopezs@fcirce.es (A.M. López-Sabirón), tgarcia@fcirce.es (T. García-Armingol), gferreira@fcirce.es (G. Ferreira). 
equipment that incorporates the most energy-efficient technologies available or eco-innovative designs considering the whole life cycle from a very early stage. In that sense, the overall objective of this work contributes not only to seek strategies to update the mainly old-aged furnaces, but also to initiate a path to ensure a successful design in case of new furnaces. This path includes a review gathering options which comprises (i) incremental improvements to existing technology and materials, and (ii) the application of significant process changes using innovative technologies that are technically reliable and have the potential to become commercially ready in the medium term. Among the wide variety of retrofitting opportunities, the present paper evaluates especially the feasibility of an innovative technology in the aluminium sector. This case study aims to assess the sustainability and efficiency in terms of environmental, energy and economic impact, by analysing a selection of the most appropriate methodologies and key indicators.

In particular, the aluminium sector represents an important part of the European industrial value chain and nowadays aluminium is the most produced non-ferrous metal [8]. The advantageous and wellknown properties of this alloy have recently spread its application in the last decades; mainly due to its strength, durability, flexibility, malleability, thermal and electrical conduction combined with its low weight [8]. In 2013, the European production ${ }^{1}$ exceeded 4.2 million tonnes of aluminium and, in particular, the extruded aluminium production was above 3 million tonnes and emitted more than 2 $\mathrm{MtCO}_{2}$ eq. $[9,10]$. Although the aluminium industry has reduced its $\mathrm{CO}_{2}$ emissions by more than $53 \%$ since 1990 and the recycling rates have extensively increased [11], much more effort is needed to fulfil the low-carbon and resource-efficient agenda. Consequently, the European Aluminium Industry's Sustainability Roadmap towards 2025, launched by European Aluminium Association (EAA) [12], aims to commit within a sustainable development and seeking innovative technologies along the aluminium value chain. Therefore, these growing environmental requirements lead the industries towards reengineering and retrofitting challenges meant to increase productivity, cost-effectiveness, energy and resource efficiency and design for lightweight recyclable materials [13].

Environmental and economic assessments are a key part for evaluating the introduction of a new process or technology, since many polices are pursuing to mitigate future climate change risks by developing strategies and technologies to reduce emissions and fossil fuels. There are several indicators to measure these emissions and therefore their impacts on the environment. For instance, $\mathrm{CO}_{2}$, sulphur or methane emissions lead to local problems related to air or soil quality and water pollution. These local environmental impacts have a significant economic dimension, as they may prove to be a decisive growth limiter in a particular location. Technical and design aspects must be combined with environmental and economic considerations for assessing novel technologies, processes and products. Consequently, the strategy should be based on an optimum environmental and economic performance assessment to evaluate environmental impacts of the new involved processes.

To do so, the European aluminium industry supports the use of the life cycle assessment methodology (LCA) [14] as a holistic environmental system analysis method, in order to promote the sustainability and life-cycle thinking [15]. In fact, LCA has already been widely used in the aluminium industry [16]:

- to make commercial strategies

- to identify the most relevant processes regarding both energy and environmental optimization and supply chain management

\footnotetext{
${ }^{1}$ The values corresponding to Europe encompasses the EU, Albania, Belarus, BosniaHerzegovina, Iceland, Macedonia, Moldavia, Norway, Serbia-Montenegro, Turkey and Ukraine.
}

\section{- to communicate the overall environmental performance}

Nevertheless, as Liu and Müller [17] presented in their review, the aluminium industry LCAs are typically accomplished from generic data, which is sometimes inaccurate, due to geographical, temporal, and technological variations; and whose coverage for some processes is still very low, so some relevant information may go undetected. To minimize these effects through the LCA approach, the life cycle inventory (LCI) of the proposed innovative technological scenarios was developed from experimental tests and then completed and compared using literature data. Finally, these results were quantified in monetary terms considering environmental externalities required for further studies framed into environmental the life cycle costs (LCC) methodology [18].

\section{Comprehensive overview of retrofitting actions in the energy intensive industries}

In search of opportunities to improve energy efficiency and reduce greenhouse gas (GHG) emissions in energy intensive industries $[19,20]$, the iron and steel sectors have been pioneers by proposing and implementing a wide range of practices and technologies not only along Europe but also worldwide [21]. Already in the 19th century, iron and steel industries developed and installed techniques of waste energy recovery [22]. In fact, Worrell, van Berkel [23] gathered many examples of energy efficient measures applied in the industrial sector, such as new technologies and processes, conversion to cogeneration, fuel switching and recycling. Furthermore, Beer, Harnisch [24] reported that the global energy efficiency in the steel sector would be improved near a $30 \%$ by 2020 using existing technologies.

Furnaces and ovens are considered to be the most energy consuming equipment, not only in steel sector, but also in other energy intensive industries. They include a very wide variety of equipment encompassing the range from the smallest laboratory ovens ( $1 \mathrm{kWh}$ ) up to the biggest cement kiln consuming up to 0.61 TWh of primary energy per year [25]. Due to the large amount of energy consumed traditionally based on fossil fuels [5], considerable GHG are emitted to the atmosphere along with other critical environmental impacts.

In this line, large efforts to improve the energy efficiency in industrial sector mainly focused on various energy savings strategies such as management, technologies and policies have been reported during the last years [1]. To this end, refurbishment actions in specific operational system based on integrated solutions combining different technologies and approaches can be considered as innovative and efficient strategies. However, despite the efforts to change the current trend, the International Energy Agency [26] reports that industry is half as energy efficient as it could be according to the thermodynamic laws. So, the opportunities to enhance the performance and reduce the environmental impact are still very high.

On the one hand, energy and resource-efficient designs and ecoinnovative thinking foster the sustainable development and green transformation. These approaches offer an opportunity for building new furnaces and ovens with the best available technology and improved performance; but investment costs or operational might be a constraint. On the other hand, retrofitting is regarded as a profitable alternative; nevertheless, the performance of these actions is not always possible [27]. There are restrictions regarding the life spam of the rest of unchanged components or is limited by the space available for a larger structure [28]. Even so, retrofitting actions can help the industries to accomplish the global commitments towards energy efficiency and low carbon production strategies, without compromising their production rates and economic balance. Hence, it is worth noting the numerous benefits of a proper retrofit strategy, which can be summarised as: 
- the optimization of already existing plant components and global performance

- the adaptation of the plant for manufacturing new or modified products

- an increase in the production rate or a decrease in the cycle time

- improvements in the energy and material resources efficiency and minimization of the losses

- a reduction in the environmental impacts

- an achievement of important cost savings

In this context, the ultimate decision between a new or retrofitted furnace must be well assessed considering the cost-effectiveness and limitations. It is at this point where this study finds an important lack of information concerning the wide range of possibility of rebuilding and retrofitting of energy intensive industrial furnace systems. The cause of this scarcity might stem from the differences along the existent furnaces types, most of which are non-standard or custom designed, requiring large efforts to perform upgrading work in the main areas of activity. The latter are namely, insulation/refractory, heating systems, advanced control and monitoring system and mechanical design. The second area has received great attention, in particular, when speaking about the feasibility of using alternative energy sources and ecoefficient waste heat recovery systems.

The industrial heating systems can be divided in combustion, electric or steam-based. The overall efficiency of an average preheating furnace is $60 \%$, where the flue gases account around $29.5 \%$ of the total energy losses of the whole production process [4]. Under this scenario, savings strategies are based on different types of equipment as recuperators, regenerators, heat wheels, economizers, etc. The energy savings of using heat recovery systems in the industrial process heating were gathered by Hasanuzzaman, Rahim [5]. For instance, they reported a percentage of saved energy up to $25 \%$ using recuperators as the main equipment with the subsequent effect in terms of GHG emission reduction.

Other option for retrofitting outdated heating systems is providing more efficient energy sources with lower GHG emissions, replacing conventional natural gas (NG) furnaces by electricity furnaces. In these latter, the energy losses are minimised by avoiding the losses through the hot exhaust gases at the same time that the efficiency of converting electricity into thermal energy is very high. Nevertheless, as explained later on, the potential positive effect on the environmental impact depends on the mix of fuel sources used for the electricity generation within the region where the installation is located.

Despite the fact that most of the existing works are focused on the steelmaking industries, most of the results may be applicable to other metal industries with some adaptations. In this vein, aluminium industry, where the case study is focused, can be considered as one of the most promising in terms of applying energy efficiency measures. Regarding the aluminium sector, and more particularly the extrusion process, the furnace system is one of the most important stages in terms of energy consumption. The furnaces are used to preheat the extrusion billet around $500{ }^{\circ} \mathrm{C}$ before being squeezed in a steel die forming the desired profile [29]. Aluminium extrusion is becoming the most viable solution to meet the specific manufacturing needs of design flexibility, cost savings, and product performance. This is the main reason why the aluminium extrusion represents $50 \%$ of total market share of all extruded metal products [30].

In this vein, the following case study aims to evaluate the replacement of those reference standard techniques, such as natural gas heating and alternating current (AC) induction heating system (Fig. 1, left) by more innovative technologies based on direct current (DC) induction. On the one hand, NG furnaces became a considerable pillar due to its more efficient combustion and lower carbon dioxide $\left(\mathrm{CO}_{2}\right)$ emissions [31]. However, it is a finite fossil energy source whose efficiency is very influenced by the non-productive heat losses. On the other hand, AC induction heats an electrically conductive material by passing an alternating current through the copper coil, thus generating a time-varying electromagnetic field [32]. This field induces Foucault currents and thereby resistive losses, releasing and distributing heat throughout the workpiece [33]. This technology allows a simple control of the current parameters which govern the main heating properties [34]. Nevertheless, the efficiency of these conventional induction heaters does not exceed $50-60 \%$ [35], since the rest of the thermal energy is removed by the cooling water or lost in the copper windings.

Later, Runde and Magnusson [32] firstly proposed an induction technique by forcing the billet to rotate in a static magnetic field created by a DC superconducting magnet [37]. The advantages of DC induction heating in efficiency and heating quality have been proved worldwide for the past decades [38]. As a superconducting magnet has no losses when carrying DC current; the efficiency of the system is expected to be up to $90 \%$. The magnetic billet heater enhances its energy efficiency and productivity, because the heating process is faster and more homogeneous. Moreover, energy penetration is three times deeper than with $\mathrm{AC}$ induction, less maintenance is needed and it works with a wide range of materials [39]. An innovative design consists of multiple parallel and independent magnetic modules rotating at different speed (Fig. 1, right), which involves two noticeable advantages [36]. Firstly, an isothermal extrusion process along the billet. Secondly, the use of independent modules drastically reduces the electromagnetic torque developed on the aluminium billet, simplifying the mechanical supports. DC induction heating is expected to fulfil the specifications of the metal extrusion industry processes. However, there are scarce experimental or commercial applications and just very few environmental assessments regarding this topic, which is fundamental and necessary for evaluating emerging technologies.

\section{Methods}

Given the lack of scientific studies, this work focuses on the environmental impacts and externalities of an aluminium billet for extrusion. Both LCA and LCC methodologies were performed considering three scenarios (conventional technology as baseline, retrofitting with DC induction maintaining also the NG furnace and only the new heating system in the last scenario) and four representative European electricity country mixes. All these results revealed the need and usefulness for both thorough external costs and environmental holistic approaches.

\subsection{LCA methodology}

The LCA is the standardised methodology used for the environmental modelling, which has an important framework provided from the ISO 14040 standard [40]. It is a holistic approach tool that assesses the potential environmental impacts and resources used throughout a product's lifecycle, from raw material acquisition, via production and use phase, to waste management; which has been used in different studies [41-43]. This methodology is referred in the International Life Cycle Data system, which is guidance for greater consistency and quality assurance, and it is synthesized in four main phases (Fig. 2).

\subsubsection{Goal and scope definition}

The objective is focused on an aluminium billet heated by a novel furnace system in order to know the environmental impact along of the cradle-to-gate life cycle. Moreover, it has been compared against the conventional one considering representative European countries with different electricity mix where the new technology could be run. The functional unit is defined as one aluminium billet, heated by the different technologies and then extruded. Fig. 3 shows the limits of the general system for processing the billet. The system boundary is defined, inside the green dotted box, to carry out the LCI for the technologies involved in this study. 

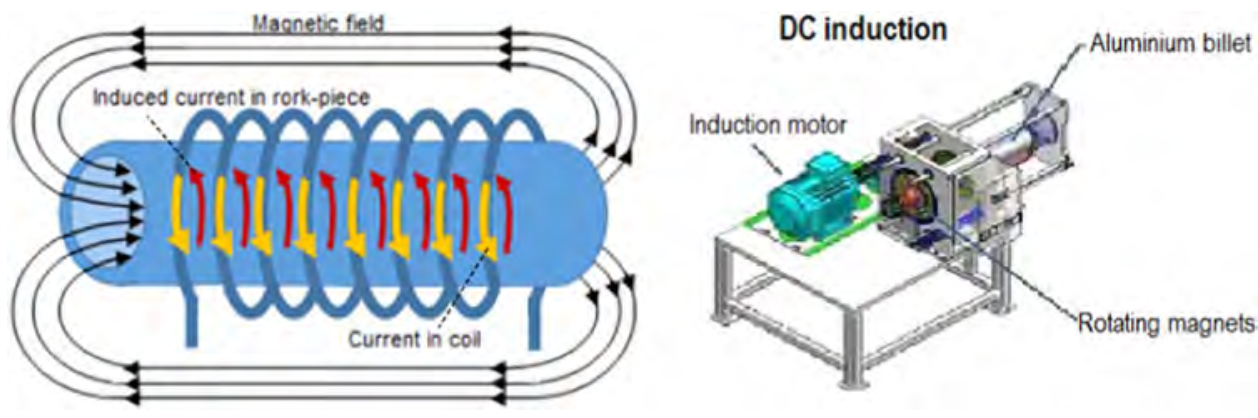

Fig. 1. AC induction (left) and DC induction (right [36]) diagrams.

\subsubsection{Life cycle inventories}

The resulting LCI depends on the type and quantity of energy, resources and materials consumed during the production and manufacturing processes of the aluminium billet. To summarise, Table 1 discusses the characteristics of the three heating technologies considered in this work as scenarios.

These activities included real data gathering collection from the sector and partially completed by in-house data expertise and also the ECOINVENT 3.0 database [44]. Some relevant data sets gathering major aluminium production processes are periodically updated by EAA [9]. LCI data are reported in

Table 2 for the heating of the aluminium billet by the furnace system. On the other hand, the inventory of the extrusion and finishing stage, which is common for the three considered scenarios, were adapted taking into account the specific requirements of the MAGNHEAT project. However, these data cannot be reproduced here in order to ensure the confidentiality.

\subsubsection{Electricity mix of the countries}

Since the electricity consumption is particularly critical for heating process (AC/DC induction furnace), as can be seen in Table 2, the electricity production mix influence has been included in the detailed analysis shown afterwards. The associated impact factor differs according to the energy sources of the electricity power generation. In order to analyse the suitability of the innovative technology, four representative European electricity country mixes were considered, namely Greece, Italy, Spain and France (Fig. 4). The sources are very variable among these countries, going from nuclear and fossil (Greece) to renewable in different shares. The diverse selection is meant to highlight the influence of the electricity mix on the environmental impact from integrating the DC induction solution intro furnaces. The average electricity mix for Europe was also presented to be compared with the rest of the European countries.

Thus, electricity consumption is reported by the LCI data associated

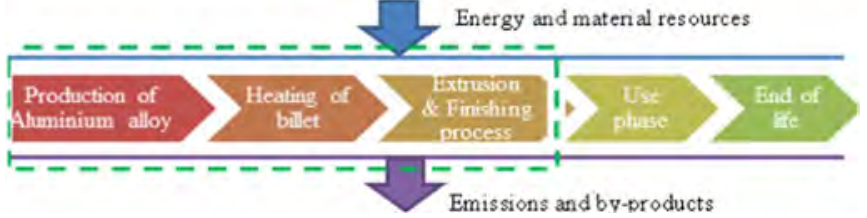

Fig. 3. Description of the system boundaries in the aluminium billet processes.

Table 1

Technologies considered to be studied in the life cycle inventories.

\begin{tabular}{|c|c|}
\hline Technology & $\begin{array}{l}\text { Summary of objective pursued with DC } \\
\text { induction }[36]\end{array}$ \\
\hline $\begin{array}{l}\text { Scenario } 1 \\
\text { Conventional technology: } \\
\text { NG + AC induction furnaces } \\
\text { Scenario } 2 \\
\text { New technology } \\
\text { (partially): } \\
\text { NG + DC induction } \\
\text { furnaces } \\
\text { Scenario } 3 \\
\text { New technology (fully): } \\
\text { DC induction furnaces } \\
\text { based on alternating } \\
\text { magnets }\end{array}$ & $\begin{array}{l}\text { - Improved technical performance: } \\
\text { flexibility in operational parameters and } \\
\text { up to } 30 \% \text { reduction in the extrusion time } \\
\text { - Higher energy efficiency up to } 90 \% \text { : the } \\
\text { expected energy savings of } 50 \% \text { will } \\
\text { reduce } \mathrm{CO}_{2} \text { emissions and other air } \\
\text { pollutants } \\
\text { - Higher flexibility with control of } \\
\text { temperature distribution and design } \\
\text { customization depending on the } \\
\text { application or material } \\
\text { - Simplicity and lower costs with respect to } \\
\text { DC induction heating approach based on } \\
\text { sophisticated superconducting coils }\end{array}$ \\
\hline
\end{tabular}

to the countries' energy mix used for the electricity generation. In Europe, the highest energy production mainly comes from renewable sources, solid fuels and nuclear sources. Greece stands out by its high share based on solid fuels, petroleum products and natural gases accounting for nearly $75 \%$ of the total electricity mix. In contrast, both Spain and Italy have a great renewable contribution up to $40 \%$, approximately. Finally, France is characterised by its enormous nuclear

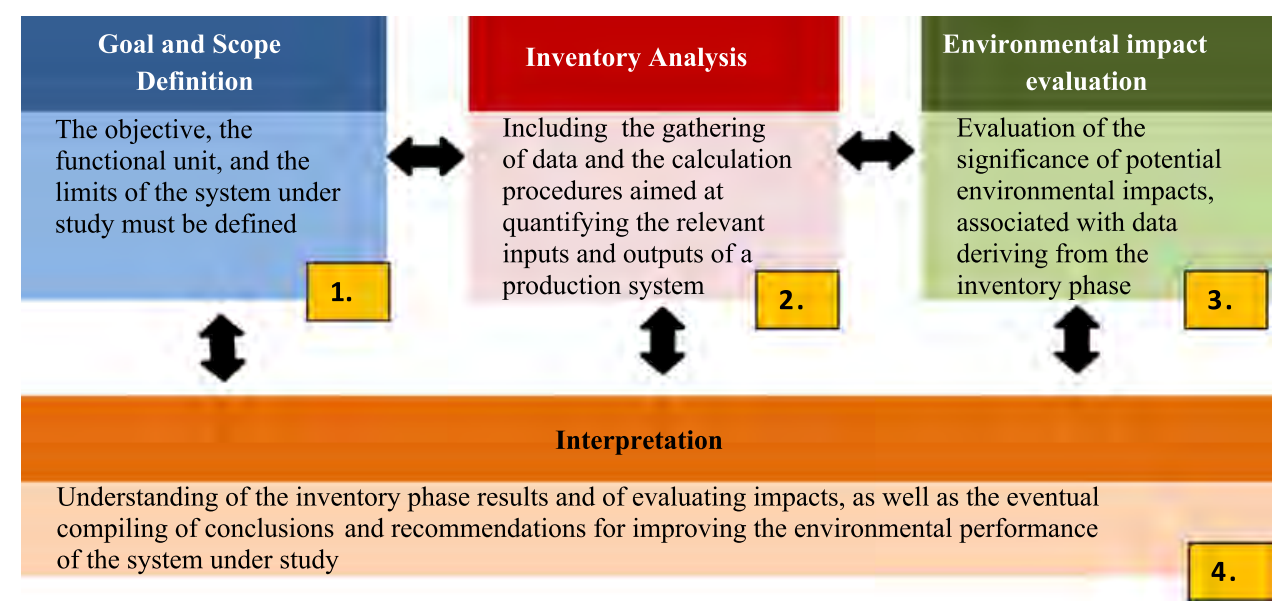

Fig. 2. Principal phases of a LCA environmental model. 
Table 2

LCI for the aluminium heating processes of billet.

\begin{tabular}{|c|c|c|c|c|}
\hline Furnace System & Units & Scenario 1 & Scenario 2 & Scenario 3 \\
\hline \multicolumn{5}{|l|}{$\begin{array}{l}\text { Inputs-Material and } \\
\text { Energy }\end{array}$} \\
\hline Primary Aluminium & kg/billet & 117.03 & 117.03 & 117.03 \\
\hline Cooling water & $\mathrm{m}^{3} /$ billet & 0.41 & 0.41 & 0.41 \\
\hline Natural gas furnace & $\mathrm{kWh} / \mathrm{billet}$ & 33 & 33 & 0 \\
\hline $\begin{array}{l}\text { Electricity for gas } \\
\quad \text { heater (preheating) }\end{array}$ & $\mathrm{kWh} / \mathrm{billet}$ & 1.38 & 1.38 & 0 \\
\hline $\begin{array}{l}\text { Electricity for } \mathrm{AC} \\
\text { induction furnace }\end{array}$ & $\mathrm{kWh} / \mathrm{billet}$ & 2.21 & 0 & 0 \\
\hline $\begin{array}{l}\text { Electricity for DC } \\
\text { induction furnace }\end{array}$ & $\mathrm{kWh} / \mathrm{billet}$ & 0 & 1.35 & 18.30 \\
\hline \multicolumn{5}{|l|}{ Outputs } \\
\hline Dirty aluminium & $\mathrm{kg} / \mathrm{billet}$ & 1.44 & 1.44 & 1.44 \\
\hline Heated finish profile & $\mathrm{kg} / \mathrm{billet}$ & 115.59 & 115.59 & 115.59 \\
\hline
\end{tabular}

input in the electricity generation. Therefore, the relevant effect in the environmental indicators have been analysed regarding the different shares in the electricity mix of each country.

\subsubsection{Cut-off criteria}

Materials and Energy: if a flow is less than 1\% of the cumulative mass/energy of all the inputs and outputs (depending on the type of flow) of the LCI model, it may be excluded due to practical limitations. The sum of the neglected material flows shall not exceed $5 \%$ of mass, energy or environmental relevance.

\subsubsection{Environmental assessment calculation}

The LCA study was developed using midpoint approach impact category indicators. Those are considered a point in the cause-effect chain somewhere between stressor (a set of conditions that may lead to
Table 3

CML-IA baseline indicator environmental impact indicators and units.

\begin{tabular}{lll}
\hline Environmental impact indicators & Units & Abbreviation \\
\hline Abiotic depletion & $\mathrm{kg} \mathrm{Sb}$ eq. & $\mathrm{AD}$ \\
Abiotic depletion (fossil fuels) & $\mathrm{MJ}$ & $\mathrm{ADF}$ \\
Global warming & $\mathrm{kg} \mathrm{CO}$ eq. & $\mathrm{GWP}(100 \mathrm{a})$ \\
Ozone layer depletion & $\mathrm{kg} \mathrm{CFC}-11$ eq. & $\mathrm{ODP}$ \\
Human toxicity & $\mathrm{kg} 1,4-\mathrm{DB}$ eq. & $\mathrm{HT}$ \\
Fresh water aquatic ecotoxicity & $\mathrm{kg} 1,4-\mathrm{DB}$ eq. & $\mathrm{FWE}$ \\
Marine aquatic ecotoxicity & $\mathrm{kg} \mathrm{1,4-DB} \mathrm{eq.}$ & $\mathrm{MAE}$ \\
Terrestrial ecotoxicity & $\mathrm{kg} 1,4-\mathrm{DB}$ eq. & $\mathrm{TE}$ \\
Photochemical oxidation & $\mathrm{kg} \mathrm{C}_{2} \mathrm{H}_{4}$ eq. & $\mathrm{PO}$ \\
Acidification & $\mathrm{kg} \mathrm{SO}_{2}$ eq. & $\mathrm{A}$ \\
Eutrophication & $\mathrm{kg} \mathrm{PO}_{4}^{3-}$ eq. & $\mathrm{E}$ \\
\hline
\end{tabular}

an impact) and impact category indicator at endpoint level (like damage to human health and to ecosystem quality) [46]. For the purpose of estimating those environmental indicators, CML 2000 [47] method is used, since it is one of the most recent and harmonised midpoint indicator approaches for LCA. The SimaPro 8.03 software [48] was used in order to construct the models, run the simulations and make the calculations for all the environmental indicators shown in Table 3. This software is a flexible and well-designed tool for LCA studies based on ISO 14040, able to simulate complex parametric models in different scenarios and calculate sensitivity and statistical analysis.

\subsection{Environmental external costs}

Moreover, LCA is structurally open to stepwise extension to an assessment that includes LCC. This is a process of economic analysis which aims to assess all costs generated in the whole product life cycle, a single phase or a combination of the different phases [49]. At present,

\section{GREECE}

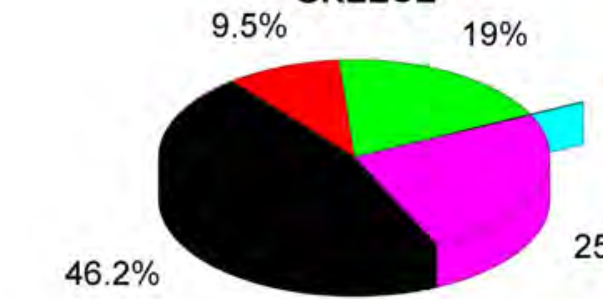

Solid fuels

Crude oil and petroleum products Natural gas and derived gases Nuclear Waste (non-renewable) Renewable energies Other

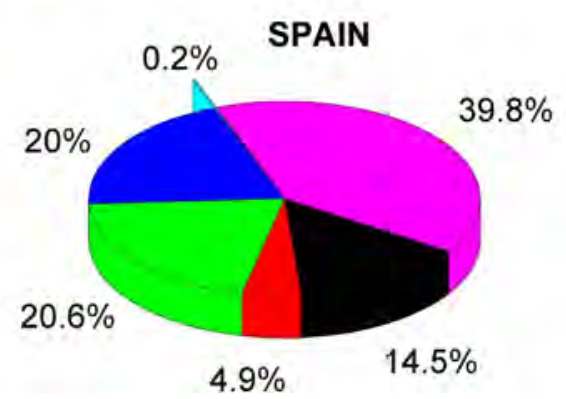

$16.6 \%$

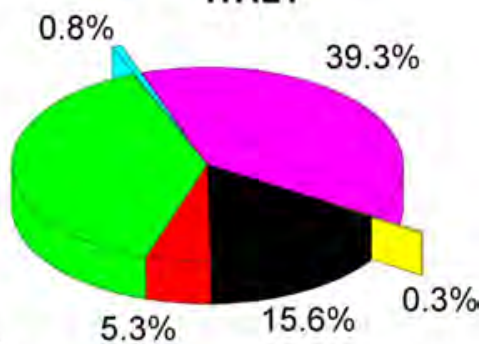

$1.9 \%$

\section{EUROPE} $26.9 \%$ $0.6 \%$

$38.7 \%$

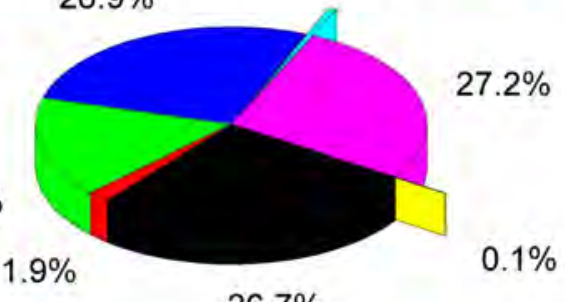

$26.7 \%$
FRANCE

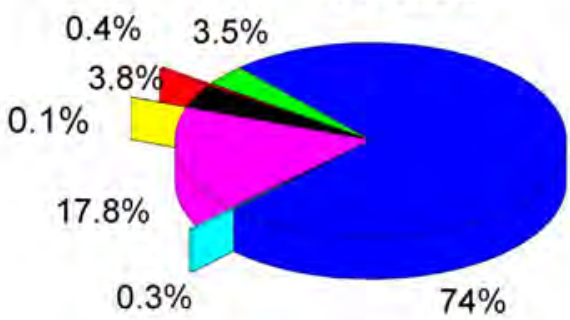

Fig. 4. Electricity mix by country in 2013 (Eurostat statistics [45]). 


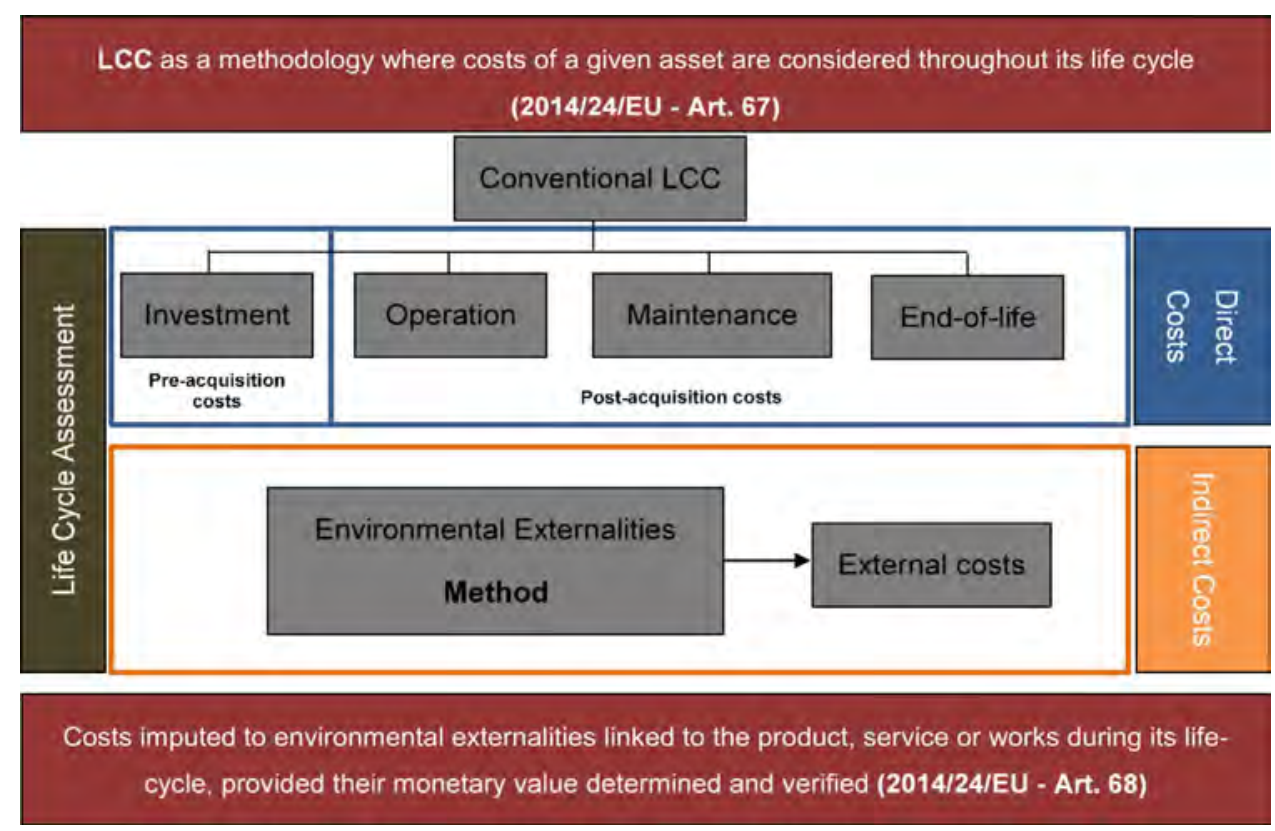

Fig. 5. Environmental LCC structure.

most widely used conventional LCC techniques are based on a purely financial valuation. This includes four main cost categories (investment, operation, maintenance and end-of-life disposal expenses); however, the value of externalities suffered by environment is not considered. In contrast to conventional LCC, this paper means to provide an added value going towards an environmental external costs approach by drawing upon the results from the environmental LCA. According to European Commission Environment [50], environmental external costs must be expressed in monetary terms, in other words, the environmental impacts to be quantified and monetarised in order to be introduced as an additional cost input in the environmental LCC structure (Fig. 5). In addition, the application of the monetarisation approach also allows the comparison among possible scenarios under a more holistic perspective, since all the environmental impact indicators are converted into the same unit of measurement [51].

Thus, this study exclusively analyses the cause-effect chain of the environmental impacts obtained from the LCI and relates them with the corresponding external costs (indirect costs). The external costs from the environmental impacts of the novel DC induction technology regarding the three different scenarios for aluminium heating have been compared to the conventional ones (gas or AC induction). As criteria, the indicators involved in the study are those leading to impacts on the environment and human health generated by air and water emissions (partially from eutrophication, others were not considered). Then, a unitary cost in euros is given based on Eq. (1) to monetarise the associated external costs (EC) weighting the severity of the effect. To do so, the external cost factors (ECF) were selected corresponding to the unit of each environmental impact indicator (EI), as shown in Table 4. The STEPWISE2006 method [52] is applied as a new approach of monetarization because it is very suitable for LCA application and it has a global scope [53].

$\mathrm{EC}=\mathrm{EI} \times \mathrm{ECF}$

\section{Results and discussion}

\subsection{LCA environmental results}

This section reports the billet LCA cradle-to-gate results considering the European country electricity mix; this is, production, heating, extrusion and finishing of the aluminium billet. First of all, the
Table 4

ECF to quantify EI used in the monetarization methodology, based on Weidema and Pizzol et al. [52,53].

\begin{tabular}{|c|c|c|}
\hline & Units & $\begin{array}{l}\text { ECF } \\
\text { EURO2016 }(€ / \mathbf{k g})^{*}\end{array}$ \\
\hline \multicolumn{3}{|l|}{ Air emission impacts } \\
\hline Ozone Depletion & $\mathrm{kg} \mathrm{CFC}_{11}$ eq. & 126 \\
\hline Acidification & $\mathrm{kg} \mathrm{SO} \mathrm{S}_{2}$ eq. & 0.19 \\
\hline Climate change (100a, direct) & $\mathrm{kg} \mathrm{CO} 2$ eq. & 0.1 \\
\hline Photochemical oxidation & $\mathrm{kg} \mathrm{C}_{2} \mathrm{H}_{4}$ eq. & 0.7 \\
\hline Human Toxicity & $\operatorname{kg} 1,4-\mathrm{DB}$ eq. & $1.9 \cdot 10^{-3}$ \\
\hline \multicolumn{3}{|l|}{ Water emission impacts } \\
\hline Eutrophication & $\mathrm{kg} \mathrm{PO}_{4}{ }^{3-}$ eq. & 1.5 \\
\hline
\end{tabular}
${ }^{*}$ Values updated from 2003 to 2016 prizes considering the average European inflation
[54].

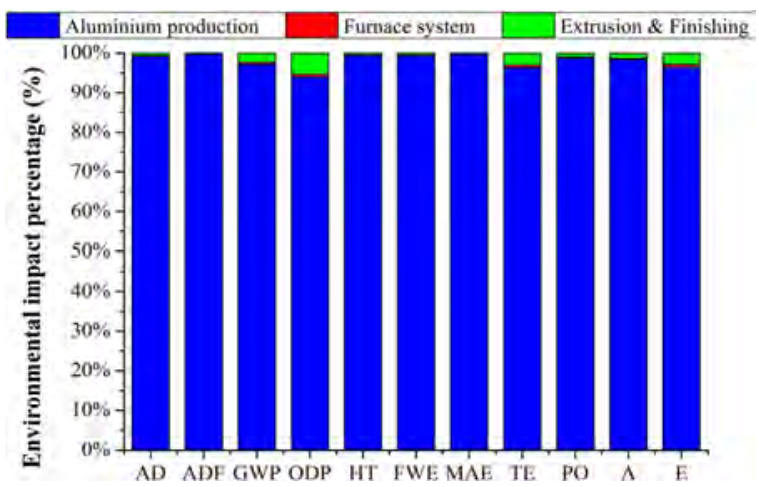

Fig. 6. Environmental impact indicators' contribution in function of the lifecycle stages under scope of scenario 3. Scenarios 1 and 2 showed similar contribution percentages.

aluminium alloy production presents the highest environmental impacts, achieving more than $90 \%$ in all indicators depicted in Fig. 6 . This is caused mainly by large amounts of energy and materials consumed during the alloyed metal production. By contrast, the furnace system and the extrusion and finishing processes present a much lower contribution regardless the scenario. According to

Table 5, it is worth mentioning that scenario 2 shows lower impact than scenario 1 in every indicator, due to the energy efficiency increase. 
Table 5

Complete LCA results for different scenarios considering the European country mix. The EI abbreviations and units are defined in Table 3.

\begin{tabular}{|c|c|c|c|c|c|}
\hline \multirow[t]{2}{*}{ EI } & \multicolumn{2}{|c|}{$\begin{array}{l}\text { Common for all } \\
\text { scenarios }\end{array}$} & \multirow{2}{*}{$\begin{array}{l}\text { Scenario } 1 \\
\\
\mathrm{NG}+\mathrm{AC} \\
\text { induction } \\
\text { furnace } \\
\text { system }\end{array}$} & \multirow{2}{*}{$\begin{array}{l}\text { Scenario } 2 \\
\text { NG+DC } \\
\text { induction } \\
\text { furnace } \\
\text { system }\end{array}$} & \multirow{2}{*}{$\begin{array}{l}\text { Scenario } 3 \\
\\
\text { DC } 100 \% \\
\text { induction } \\
\text { furnace } \\
\text { system }\end{array}$} \\
\hline & $\begin{array}{l}\text { Aluminium } \\
\text { production }\end{array}$ & $\begin{array}{l}\text { Extrusion } \\
\text { and } \\
\text { Finishing }\end{array}$ & & & \\
\hline $\mathrm{AD}$ & $1.06 \cdot 10^{-3}$ & $8.30 \cdot 10^{-6}$ & $3.49 \cdot 10^{-8}$ & $3.49 \cdot 10^{-8}$ & 0.00 \\
\hline $\mathrm{ADF}$ & $2.03 \cdot 10^{4}$ & 45.50 & 3.95 & 3.92 & 0.66 \\
\hline GWP & $1.63 \cdot 10^{3}$ & 38.80 & 8.74 & 8.35 & 8.55 \\
\hline ODP & $6.10 \cdot 10^{-5}$ & $3.47 \cdot 10^{-6}$ & $1.11 \cdot 10^{-7}$ & $9.12 \cdot 10^{-8}$ & $4.37 \cdot 10^{-7}$ \\
\hline $\mathrm{HT}$ & $2.13 \cdot 10^{3}$ & 10.90 & 0.68 & 0.56 & 2.58 \\
\hline FWE & $1.28 \cdot 10^{3}$ & 6.61 & 0.41 & 0.34 & 1.50 \\
\hline MAE & $2.23 \cdot 10^{7}$ & $4.67 \cdot 10^{4}$ & $2.54 \cdot 10^{3}$ & $2.02 \cdot 10^{3}$ & $1.11 \cdot 10^{4}$ \\
\hline $\mathrm{TE}$ & 0.30 & $9.47 \cdot 10^{-3}$ & $8.95 \cdot 10^{-4}$ & $7.99 \cdot 10^{-4}$ & $2.07 \cdot 10^{-3}$ \\
\hline PO & 0.73 & $7.26 \cdot 10^{-3}$ & $5.33 \cdot 10^{-4}$ & $4.61 \cdot 10^{-4}$ & $1.57 \cdot 10^{-3}$ \\
\hline A & 12.90 & 0.18 & $9.60 \cdot 10^{-3}$ & $7.81 \cdot 10^{-3}$ & $3.86 \cdot 10^{-2}$ \\
\hline $\mathrm{E}$ & 3.57 & 0.11 & $5.88 \cdot 10^{-3}$ & $4.69 \cdot 10^{-3}$ & $2.54 \cdot 10^{-2}$ \\
\hline
\end{tabular}

On the other hand, while scenario 3 reduces the absolute impact in indicators such as abiotic depletion, there is an increase in most indicators with regard to the other scenarios due to the high use of electricity. At first sight, scenario 2 would be the most environmentally efficient for the European country mix, though some indicators increased.

Since the analysis is focused on delving in the suitability of the application between conventional and novel retrofitting heating technologies, just the furnace systems of the scenarios are considered hereafter. Then, the results concerning the quantification of the CML indicators were calculated and shown in Table 6 for the furnace system of the three scenarios considering the four countries.

On the one hand, similarly to what happened with the European electricity mix, the values of scenario 2 shows lower impact than scenario 1 in every indicator, proofing the benefits of the DC induction technology when AC induction is replaced. On the other hand, the relative percentages of these two scenarios are very similar within a country; while greater differences are observed regarding scenario 3, mainly because of the amount of electricity is used for heating the aluminium instead of fossil fuels (NG) consumption.

According to Fig. 7, there is a relevant variation depending on the country mix, but for the abiotic depletion indicator. Specially, Greece presents the highest values in most environmental impact indicators due to the $50 \%$ contribution in the electricity mix of fossil fuels, especially lignite and coal; except for ozone depletion and abiotic depletion fossil. Indeed, the human toxicity, eutrophication, fresh water and terrestrial ecotoxicity indicators are the most significant cases, as the relative contribution of Italy, Spain and France did not overpass a maximum of $10 \%$ in respect with the Greek country mix. However, these differences among countries are not so weighty in some indicators, such as global warming, ozone depletion, photochemical oxidation and acidification, where the country mix of Spain and Italy show also an important impact.

Similar to other technologies previously analysed in literature [55] which evidence the high relevance of location in the environmental impact associated to the processes, the result obtained in this study confirmed that the country mix existing is also an important variable for the technology analysed in this paper.

Then, Fig. 8 depicts the LCA results of the furnace system in function of the country mix. Overall, it is appreciated that the scenario 2 reported reductions up to $23 \%$ in most indicators for every country, respect to the conventional furnace system of scenario 1, thanks to the better energy efficiency. Apart from that, scenario 3 showed the best results for the abiotic depletion of elements and the abiotic depletion of fossil fuels, because no NG is consumed. In spite of this, it can be seen a disadvantageous increase in most environmental impact indicators of all the countries. The key reason is the great augmentation of the electricity consumption as the main heating source in scenario 3 . Hence, the application of the novel DC induction technology must be well assessed to assure an optimization of the environmental efficiency.

Firstly, it is clear that Greece presents the greatest contrasts when the billet is heated only by DC induction (scenario 3) because of the dependence on electricity based on fossil fuel sources, which accounts nearly $50 \%$. For instance, the GWP indicator was reduced around $40 \%$ when the NG furnace was complemented by DC induction (scenario 2); while the rest of indicators showed even a larger reduction, up to $85 \%$ (eutrophication and marine aquatic ecotoxicity).

Secondly, Spain and Italy's figures indicate an overall resemblance due to the similarities in the electricity mix shares. In these cases, the scenario 2 would be the most environmentally profitable in most impact indicators, but the abiotic depletion. However, specifically in the global warming and the terrestrial ecotoxicity indicators, the three scenarios exhibit almost the same impact. Nevertheless, it is worth noting that in the case of Spain, the scenario 3 reduces the GHG emissions. The global warming indicator decreases a $25 \%$ when compared with scenario 1 and approximately a $5 \%$ in respect with scenario 2, due to the nuclear energy used in the electricity generation (20\%). This fact is even more evident with the country mix of France, with a predominantly nuclear source achieving the $75 \%$ share. When only electricity is consumed for DC induction technology (scenario 3), the global warming indicator notably decreases down to a $20 \%$ respect to the conventional technology (scenario 1). Consequently, reducing the $\mathrm{CO}_{2}$ eq. emissions involved in the billet heating process, showing the lowest relative and absolute values.

Table 6

Summary of LCA results for the furnace system technologies in function of the country. The EI abbreviations and units are defined in Table 3.

\begin{tabular}{|c|c|c|c|c|c|c|c|c|c|c|c|c|}
\hline \multirow[t]{2}{*}{ EI } & \multicolumn{3}{|c|}{ Greece } & \multicolumn{3}{|l|}{ Italy } & \multicolumn{3}{|c|}{ Spain } & \multicolumn{3}{|c|}{ France } \\
\hline & $\mathbf{S 1}$ & S2 & S3 & $\mathbf{S 1}$ & S2 & S3 & $\mathbf{S 1}$ & S2 & S3 & $\mathbf{S 1}$ & S2 & S3 \\
\hline $\mathrm{AD} \times 10^{8}$ & 3.49 & 3.49 & 0.0 & 3.49 & 3.49 & 0.0 & 3.49 & 3.49 & 0.0 & 3.49 & 3.49 & 0.0 \\
\hline $\begin{array}{l}\mathrm{ADF} \\
\times 10^{2}\end{array}$ & 382 & 382 & 1.44 & 388 & 387 & 31.5 & 394 & 391 & 61.9 & 383 & 383 & 6.73 \\
\hline GWP & 10.1 & 9.35 & 15.3 & 8.89 & 8.46 & 9.30 & 8.31 & 8.02 & 6.30 & 7.36 & 7.30 & 1.43 \\
\hline ODP $\times 10^{8}$ & 12.9 & 10.4 & 52.7 & 17.1 & 13.6 & 74.2 & 11.9 & 9.66 & 47.4 & 3.96 & 3.65 & 6.66 \\
\hline $\mathrm{HT}$ & 2.43 & 1.89 & 11.6 & 0.36 & 0.32 & 0.93 & 0.42 & 0.36 & 1.23 & 0.39 & 0.34 & 1.11 \\
\hline FWE & 1.72 & 1.34 & 8.24 & 0.21 & 0.19 & 0.45 & 0.19 & 0.18 & 0.39 & 0.16 & 0.15 & 0.18 \\
\hline MAE $\times 10^{-3}$ & 10.5 & 8.05 & 51.9 & 1.37 & 1.14 & 5.09 & 1.71 & 1.39 & 6.81 & 0.74 & 0.66 & 1.83 \\
\hline $\mathrm{TE} \times 10^{4}$ & 23.4 & 18.9 & 94.8 & 6.16 & 5.87 & 6.29 & 6.28 & 5.96 & 6.89 & 6.89 & 6.42 & 10.0 \\
\hline $\mathrm{PO} \times 10^{4}$ & 9.01 & 7.40 & 34.6 & 5.21 & 4.51 & 15.1 & 5.24 & 4.54 & 15.2 & 2.84 & 2.71 & 2.82 \\
\hline $\mathrm{A} \times 10^{3}$ & 19.0 & 14.9 & 86.7 & 9.15 & 7.46 & 36.2 & 10.0 & 8.14 & 40.8 & 3.56 & 3.21 & 7.43 \\
\hline $\mathrm{E} \times 10^{3}$ & 26.3 & 20.2 & 130 & 2.79 & 2.34 & 9.54 & 2.35 & 2.01 & 7.30 & 1.43 & 1.31 & 2.54 \\
\hline
\end{tabular}


Scenario 1

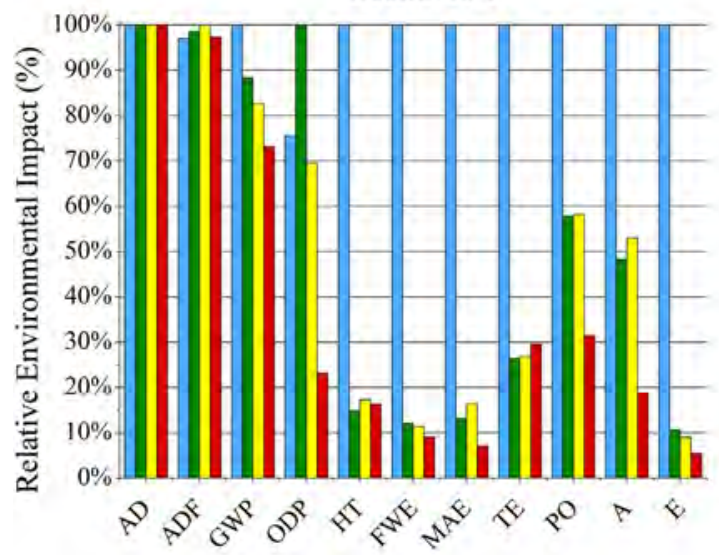

Scenario 3

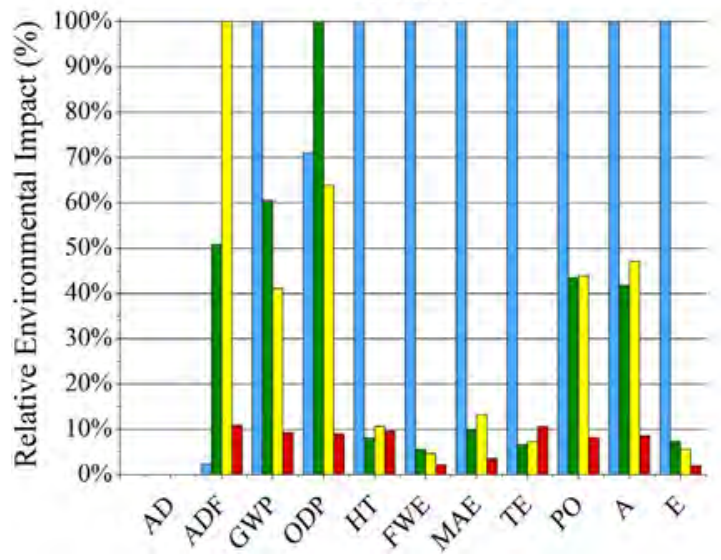

Scenario 2

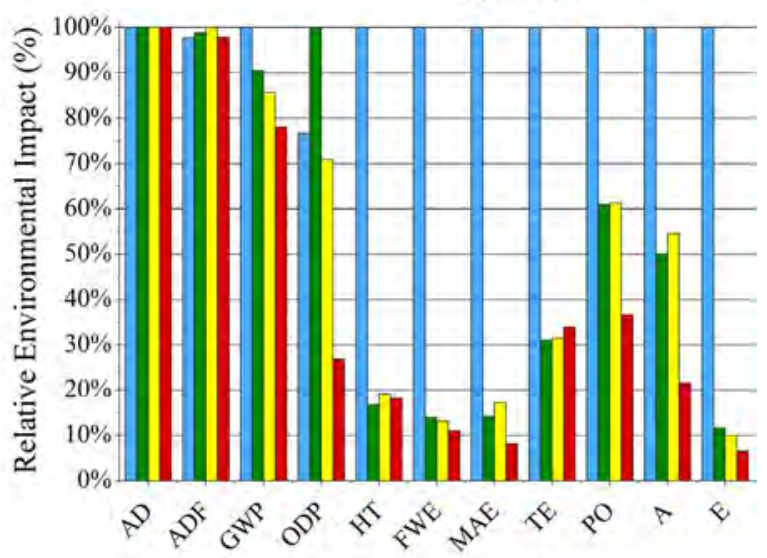

Fig. 7. Relative contribution of EI of the furnace system gathered by scenarios.

\subsection{Monetarization results}

The monetarization involving the environmental external costs provides a useful and handy tool for the companies, which can be used for optimization and decision support purposes, and, furthermore, it is a relevant part of the environmental LCC. So, the results of LCA are linked to the indirect costs associated to the processes inside the system boundaries depicted Fig. 3. To do so, all the EI of the furnace systems defined in

Table 5 considering the country mix of Europe, were converted into monetary values using the ECF factors reported in Table 4. As a result, Table 7 shows the EC values, that is to say, environmental externalities costs concerning the three scenarios and the average European country mix.

The above results are necessary for a comprehensive understanding of both the environmental and economic consequences of using different technologies in furnace system. Nevertheless, it is not so evident to determine which scenario is better considering the environmental results of the LCA presented in Table 5. The challenge from the environmental point of view is the overall quantification of the impacts within an average European electricity mix, as some of them show worse or better results depending on the scenario. Compounding this difficulty is the fact that each environmental impact is measured in a different unit and therefore, they cannot be directly added.

Thus, the monetarisation approach proposed in this work aims to determine the most environmentally efficient solution. To that end, it was estimated the potential external costs related to mitigation of the burden on the human health and ecosystems, caused by different heating process technologies. As observed in Table 7, the novel DC induction technology of scenario 2 has a total external cost approxi- mately $5 \%$ lower than the aluminium heating based on traditional AC induction. The main difference among the technologies is due to reduction in terms of climate change indicator, in which the scenario 2 showed the lowest impact. However, despite the intrinsic importance of climate change (more than 94\% contribution), the effect of other indicators cannot be neglected, in particular, the eutrophication indicator accounts around a $5 \%$ on the global environmental cost of scenario 3. Hence, more attention should be also given to eutrophication, acidification and human toxicity indicators when the heating process is exclusively based on DC induction generated by electricity.

Finally, it must be noted that the results of the environmental externality costs is expected to vary as a function of the country mix, as a key factor. Those scenarios which reduce the GWP indicator involve an important decrease on the EC of that scenario. As a consequence, the scenario 2 would be the most cost-effective case from the environmental point of view in Greece and Italy; while in Spain and France the best alternative would be the heating $100 \%$ based on DC induction.

\section{Conclusions}

Among all the reviewed retrofitting actions in the energy intensive sectors, a case study focused on the analysis of the feasibility of applying a retrofitting strategy has been performed within the aluminium extrusion process. First of all, an environmental study according to cradle-to-gate LCA methodology allowed comparing different heating process technologies, taking into account the electricity mix of four European countries.

Particularly, Greece presented the highest values in most environmental impact indicators for every scenario. However, other indicators, such as global warming or ozone depletion, should not be neglected in 

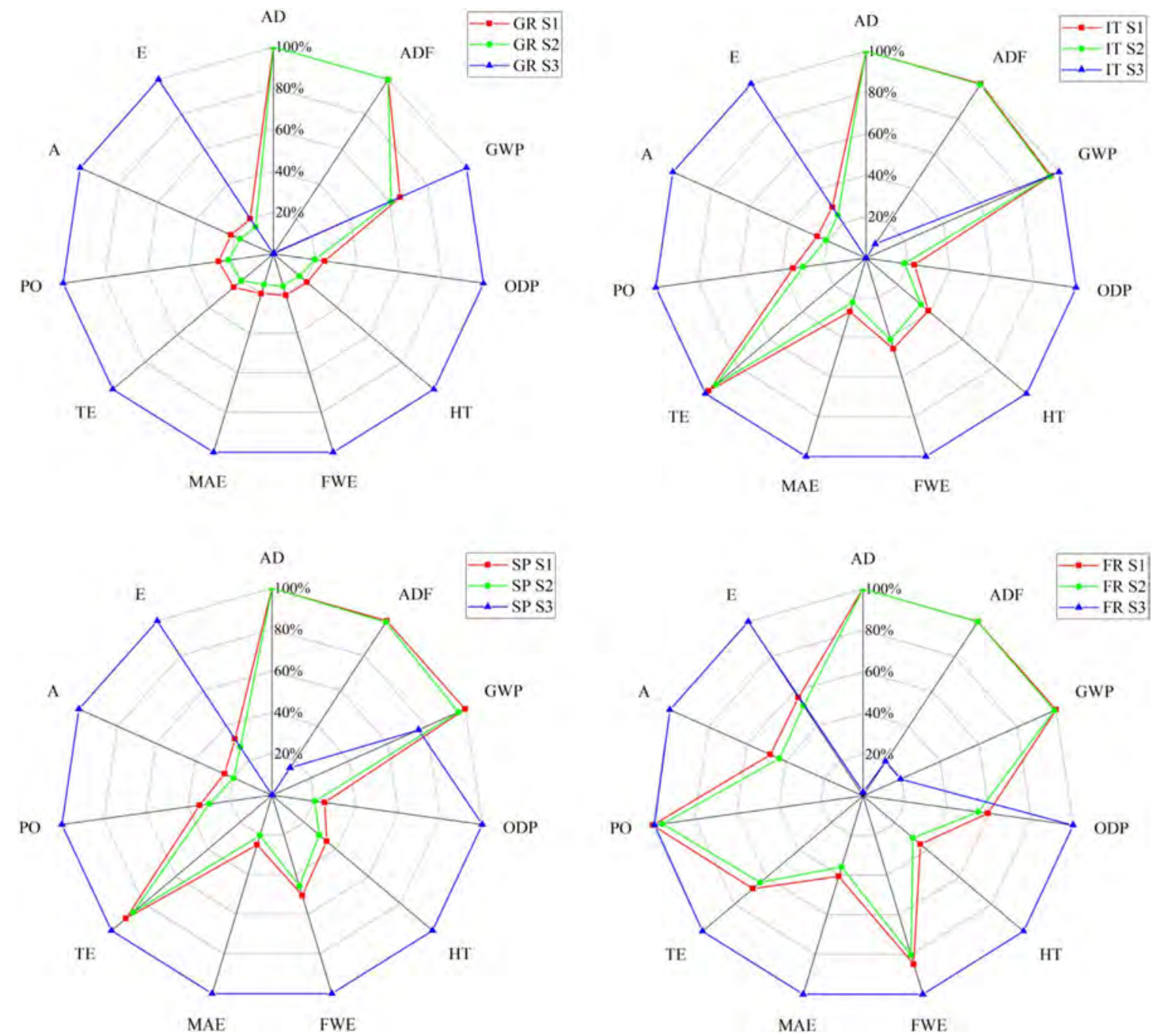

Fig. 8. Relative contribution of EI in the furnace system gathered by country mixes. Red: S1, Green: S2 and Blue: S3.

Table 7

Monetary value of LCA external costs (EC) of the furnace system technologies considering the European country mix.

\begin{tabular}{llll}
\hline & EC Scenario 1 & EC Scenario 2 & EC Scenario 3 \\
\hline ODP & $1.40 \cdot 10^{-5}$ & $1.15 \cdot 10^{-5}$ & $5.50 \cdot 10^{-5}$ \\
A & $1.81 \cdot 10^{-3}$ & $1.47 \cdot 10^{-3}$ & $7.28 \cdot 10^{-3}$ \\
GWP & 0.88 & 0.84 & 0.86 \\
PO & $3.75 \cdot 10^{-4}$ & $3.25 \cdot 10^{-4}$ & $1.11 \cdot 10^{-3}$ \\
HT & $1.32 \cdot 10^{-3}$ & $1.09 \cdot 10^{-3}$ & $5.00 \cdot 10^{-3}$ \\
E & $8.88 \cdot 10^{-3}$ & $7.08 \cdot 10^{-3}$ & $3.83 \cdot 10^{-2}$ \\
Total (E/billet) & $\mathbf{0 . 8 9}$ & $\mathbf{0 . 8 5}$ & $\mathbf{0 . 9 1}$ \\
\hline
\end{tabular}

Spain and Italy. The study proofed the benefits of DC induction technology showing a lower impact (up to 23\%) in most indicators when replacing $\mathrm{AC}$ induction. When the billet was fully heated by DC induction, most indicators revealed an important increase due to the intensive use of electricity. On the contrary, the global warming indicator notably decreased around $80 \%$ in France; while it increased $50 \%$ in Greece with regard to the conventional one. Furthermore, a monetarization approach was addressed to calculate the externalities cost of each scenario. The innovative DC induction system in scenario 2 was the lowest EC, $(0.85 €$ per aluminium billet as European average). This decrease was mainly attributed to the GHG reduction caused by the energy efficiency enhancement of this retrofitting technology. So, it is worth mentioning that the decision-making is strongly influenced by the electricity mix.

In this vein, the application of a retrofitting or innovative technology must be well assessed under a holistic multi-objective approach (energy, environmental impact and cost-effectiveness) to obtain a conclusive result. As concluded by the case study, countries with low $\mathrm{CO}_{2}$ eq. emission factors, like Spain and France, presented the best option if the innovative DC induction is fully applied. On the contrary, retrofitting heating systems with DC induction is most suitable for countries with high share of carbon-rich sources (more than $0.7 \mathrm{t} \mathrm{CO}_{2}$ eq. / $\mathrm{MWh}_{\text {elect }}$ ).

\section{Acknowledgements}

The research leading to these results has received funding from the European Union LIFE+ Framework Programme (LIFE+2013) under grant agreement $n^{\circ}$ LIFE13 ENV/IT/000538 - MAGNHEAT project. Authors thanks to the project partners for providing support to this research.

\section{References}

[1] Abdelaziz EA, Saidur R, Mekhilef S. A review on energy saving strategies in industrial sector. Renew Sust Energy Rev 2011;15:150-68.

[2] Friends of the Earth. Energy intensive industry and climate change. London, UK; 2011.

[3] Napp TA, Gambhir A, Hills TP, Florin N, Fennell PS. A review of the technologies, 
economics and policy instruments for decarbonising energy-intensive manufacturing industries. Renew Sust Energy Rev 2014;30:616-40.

[4] Si M, Thompson S, Calder K. Energy efficiency assessment by process heating assessment and survey tool (PHAST) and feasibility analysis of waste heat recovery in the reheat furnace at a steel company. Renew Sust Energy Rev 2011;15:2904-8.

[5] Hasanuzzaman M, Rahim NA, Hosenuzzaman M, Saidur R, Mahbubul IM, Rashid MM. Energy savings in the combustion based process heating in industrial sector. Renew Sust Energy Rev 2012;16:4527-36.

[6] VDMA Publication. Energy efficiency of industrial furnaces; 2009. 〈http://www. ecfia.eu/benefits_ee.htm $>$ [accessed 13 December 2016].

[7] Worrell E, Galitsky C, Masanet E, Graus W. Energy efficiency improvement and cost saving opportunities for the glass industry. In: ENERGY STAR, editor. Berkeley (California): Berkely National Laboratory; 2008.

[8] Aluminium Stewardship Initiative. ASI Performance Standard; 2016. 〈http:// aluminium-stewardship.org/about-asi/aluminium-and-sustainability/ $\rangle$ [accessed 23 May 2016].

[9] European Aluminium Association (EAA). Environmental profile report for the european aluminium industry Brussels, Belgium; 2013.

[10] The International Aluminium Institute. Aluminium material flows in Europe in 2013. . 〈http://www.world-aluminium.org/statistics/2014〉.

[11] European Aluminium Association (EAA). Sustainable development indicators for the aluminium industry in Europe. Brussels, Belgium; 2012.

[12] European Aluminium Association (EAA). The European aluminium Industry's sustainability roadmap towards 2025. Brussels, Belgium; 2015.

[13] Garbacz P, Giesko T, Mazurkiewicz A. Inspection method of aluminium extrusion process. Arch Civ Mech Eng 2015;15:631-8.

[14] Guinée JB, Heijungs R, Huppes G, Zamagni A, Masoni P, Buonamici R, et al. Life cycle assessment: past, present, and future. Environ Sci Tech Lib 2011;45:90-6.

[15] de Schrynmakers P. Life cycle thinking in the aluminium industry. Int J Life Cycle Ass 2009; 14:2-5.

[16] Rebitzer G, Buxmann K. The role and implementation of LCA within life cycle management at Alcan. J Clean Prod 2005;13:1327-35.

[17] Liu G, Müller DB. Addressing sustainability in the aluminum industry: a critical review of life cycle assessments. J Clean Prod 2012;35:108-17.

[18] European Commission Environment. Life-cycle costing; 2015. 〈http://ec.europa. eu/environment/gpp/lcc.htm $\rangle$ [accessed 24 Feburary 2016].

[19] Bernstein L, Roy J, Delhotal KC, Harnisch J, Matsuhashi R, Price L. Industry. In: Press CU, editor. Climate change 2007: mitigation. Contribution of working group III to the fourth assessment report of the intergovernmental panel on climate change. Cambridge, United Kingdom/New York, NY, USA; 2007. p. 449-96.

[20] Gale J, Freund F. Greenhouse gas abatement in energy intensive industries; 2000.

[21] He K, Wang L. A review of energy use and energy-efficient technologies for the iron and steel industry. Renew Sust Energy Rev 2017;70:1022-39.

[22] Bergmeier M. The history of waste energy recovery in Germany since 1920. Energy 2003;28:1359-74.

[23] Worrell E, van Berkel R, Fengqi Z, Menke C, Schaeffer R, Williams RO. Technology transfer of energy efficient technologies in industry: a review of trends and policy issues. Energy Policy 2001;29:29-43.

[24] Beer Jd, Harnisch J, Kerssemeeckers M, IEAGG R \& D Programme , Ecofys . Greenhouse gas emissions from iron and steel production. Utrecht, The Netherlands: ECOFYS; 1999 .

[25] Goodman P, Robertson C, Skarstein A, Lyons L, Pahal S. Sustainable Industrial Policy - Building on the Eco-design Directive - Energy-Using Products Group Analysis/2 - Lot 4: Industrial and Laboratory Furnaces and Ovens. Surrey, England: ERA Technology and BIO intelillence service; 2012. p. 469.

[26] International Energy Agent (IEA). Energy technology perspective 2006: scenario and strategies to 2050. Pais: IEA; 2006.

[27] Wesseling JH, Lechtenböhmer S, Åhman M, Nilsson LJ, Worrell E, Coenen L. The transition of energy intensive processing industries towards deep decarbonization: characteristics and implications for future research. Renew Sust Energy Rev 2017;79:1303-13.

[28] ERA Technology - EC DG Enterprise. Sustainable Industrial Policy - Building on the Eco-design Directive - Energy-using Products Group Analysis/2"; 2009.

[29] Education and Training Committee (ETC) of the European Aluminium Association
(EAA) and MATTER at the University of Liverpool. aluMATTER; 2016. 〈http:// aluminium.matter.org.uk/> [accessed .25/03/2016].

[30] SPECTRA Aluminium products. The Benefits of Aluminum Extrusion in Industry, $\langle\mathrm{http}: / / w w w . s p e c t r a a l u m i n u m . c o m / a l u m i n u m-e x t r u s i o n-i n-i n d u s t r y . h t m l\rangle ;$ [accessed .22/12/2016]

[31] Mazyan W, Ahmadi A, Ahmed H, Hoorfar M. Market and Technology Assessment of Natural Gas Processing: a review. J Nat GasSci Eng 2016:30.

[32] Runde M, Magnusson N. Induction heating of aluminium billets using superconducting coils. Phys C: Supercond 2002;372-376(Part3):1339-41.

[33] Kranjc M, Zupanic A, Miklavcic D, Jarm T. Numerical analysis and thermographic investigation of induction heating. Int J Heat Mass Transf 2010;53:3585-91.

[34] Bodart O, Boureau A, Touzani R. Numerical investigation of optimal control of induction heating processes. Appl Math Model 2001;25:697-712.

[35] Zerbetto M, Forzan M, Dughiero F. Permanent magnet heater for a precise control of temperature in aluminum billets before extrusion. Mater Today 2015;2:4812-9.

[36] Inovalab. LIFE-MAGNHEAT project; 2013. 〈www.magnheat.com/the-project〉 [accessed .04/04/2016].

[37] Fabbri M, Morandi A, Ribani PL. DC induction heating of aluminum billets using superconducting magnets. COMPEL 2008;27:480-90.

[38] Yang J, Gao H, Wang YW, Xu DQ, Hong Z, Jin Z, et al. Design and experimental results of a DC induction heater prototype for aluminum billets. IEEE Trans Appl Supercond 2014;24:1-4.

[39] Bublik J. Magnetic heating of billets. Intensive Programme Renewable Energy Sources. Czech Republic; 2010.

[40] International Organization for Standardization. ISO 14040:2006, Environmental management- life cycle assessment- principles and framework. Geneva, Switzerland; 2006.

[41] Ferreira VJ, López-Sabirón AM, Royo P, Aranda-Usón A, Ferreira G. Integration of environmental indicators in the optimization of industrial energy management using phase change materials. Energy Convers Manag 2015;104:67-77.

[42] Ferreira VJ, Sáez-De-Guinoa Vilaplana A, García-Armingol T, Aranda-Usón A Lausín-González C, López-Sabirón AM, et al. Evaluation of the steel slag incorporation as coarse aggregate for road construction: technical requirements and environmental impact assessment. J Clean Prod 2016;130:175-86.

[43] Royo P, Ferreira VJ, López-Sabirón AM, Ferreira G. Hybrid diagnosis to characterise the energy and environmental enhancement of photovoltaic modules using smart materials. Energy 2016;101:174-89.

[44] ETH-Swiss Centre for Life Cycle Inventories. EcoinventDatabase; 2013. 〈www. ecoinvent.org $>$ [accessed 24 Febuary 2016].

[45] Eurostat. Your key to European statistics; 2013. 〈http://ec.europa.eu/eurostat〉 [accessed .24/02/2016].

[46] Tukker A. Life cycle assessment as a tool in environmental impact assessment. Eur Env Imp Assess 2000;20:435-56.

[47] Jeroen G. Handbook on life cycle assessment-operational guide to the ISO standards. Int J Life Cycle Ass, 6 2001; 2001. p. 255.

[48] PRé Consultants. SimaPro 8 LCA software. The Netherlands; 2015.

[49] Carlsson Reich M. Economic assessment of municipal waste management systems case studies using a combination of life cycle assessment (LCA) and life cycle costing (LCC). J Clean Prod 2005;13:253-63.

[50] European Commission Environment. Life-cycle costing; 2015. 〈http://ec.europa eu/environment/gpp/lcc.htm $\rangle$ [accessed 2016]

[51] Lindberg J. Monetarization - a life cycle assessment weighting methodology. Göteborg, Sweden: Chalmers University of Technology; 2014.

[52] Weidema BP. Using the budget constraint to monetarise impact assessment results. Ecol Econ 2009;68:1591-8.

[53] Pizzol M, Weidema B, Brandão M, Osset P. Monetary valuation in life cycle assessment: a review. J Clean Prod 2015;86:170-9.

[54] Inflation.eu. Worldwide InflationData; 2016. (www.inflation.eu/inflation-rates/ europe/historic-inflation/hicp-inflation-europe.aspx $>$ [accessed 04 April 2016]

[55] López-Sabirón AM, Fleiger K, Schäfer S, Antoñanzas J, Irazustabarrena A, ArandaUsón A, et al. Refuse derived fuel (RDF) plasma torch gasification as a feasible route to produce low environmental impact syngas for the cement industry. Waste Manag Res 2015;33:715-22. 